\title{
Exhaust emissions from farm tractors operating in urban areas
}

\author{
P. Lijewski \& J. Merkisz \\ Institute of Combustion Engines and Transport, \\ Poznan University of Technology, Poland
}

\begin{abstract}
In urban areas, the most frequently operated type of vehicles are the on-road vehicles such as passenger vehicles and city buses. In many agglomerations (Berlin, Munich) zones have been introduced where only exhaust emissioncompliant vehicles are permitted. If they fail to meet the set standards for a given zone an appropriate charge is incurred. We should remember, however, that in city centers non-road vehicles are also used for specific work such as the maintenance of green areas. Unfortunately, these types of vehicles are fitted with engines that are technologically obsolete in comparison to modern on-road vehicles. Hence, the exhaust emissions from the non-road vehicles are far greater as compared to regular vehicles, which is confirmed by much more liberal emission standards for this group. This paper discusses this issue in detail and presents the results of the exhaust emission tests carried out under actual operating conditions (maintenance of green areas). In order to better depict the situation the results were compared with the exhaust emissions of passenger vehicles also obtained under actual traffic conditions.

Keywords: exhaust emissions, farm tractors, operation in urban areas.
\end{abstract}

\section{Introduction}

The protection of natural environment against negative impact of transport requires complex solutions. In combustion engines these solutions should include the optimization of the combustion process, the application of after treatment systems (DPF, SCR), the use of proper fuels (fuel of low sulfur content). Non-road vehicles are fitted with diesel engines mainly. This results from the advantageous operating parameters of these engines and relatively low 
fuel consumption. An important thing however is the impact of diesel engines on the natural environment. According to research published in [1-5] the exhaust gas from diesel engines is very harmful to human health. The results of research conducted by IARC (International Agency for Research on Cancer), a member of WHO (World Health Organization), in the report published in June 2012 qualified diesel exhaust gases to a group of carcinogenic factors. It is noteworthy that the exhaust emission limits for non-road vehicles for many years have been very liberal as opposed to the on-road vehicles. An important issue is the fact that non-road vehicles are beyond any control in terms of exhaust emissions. Current legal regulations do not provide for the obligation of non-road vehicles exhaust emission testing, hence they may pose a serious threat to the natural environment and human health. This problem is of particular significance in the urban areas where smog threat exists and the number of non-road vehicles is getting higher. These vehicles are used for the maintenance of green areas, street cleaning, let alone construction works (construction machinery). The aim of this paper is to draw attention to the exhaust emissions of non-road vehicles in urban areas.

\section{Testing methods and equipment}

In order to assess the exhaust emissions from non-road vehicles tests were carried out on a farm tractor and a passenger vehicle and a comparative analysis of the results was performed. The tests were performed under actual operating conditions of these vehicles in real traffic. The farm tractor transported a load of the weight of approximately $4000 \mathrm{~kg}$, which is not a particularly heavy load for this type of machine. Green area maintenance works are associated with carriage of rather moderate loads, hence the choice of this weight. The basic technical specifications of vehicles used in research and its engine have been shown in table 1 and the view of the machine and the testing equipment in figure 1.

Table 1: $\quad$ Basic technical specifications of vehicles.

\begin{tabular}{|c|c|c|}
\hline $\begin{array}{c}\text { Data of the power } \\
\text { unit }\end{array}$ & $\begin{array}{c}\text { Tractor } \\
\text { CI engine, } 6.8 \mathrm{dm}^{3}- \\
\mathrm{kW} \text {, turbocharge VGT, } \\
\text { common rail system }\end{array}$ & $\begin{array}{c}\text { CI engine, } 2.0 \mathrm{dm}^{3} \text {, power } \\
-137 \mathrm{~kW} \text {, turbocharge } \\
\text { VGT, common rail }\end{array}$ \\
\hline Mileage & 2 years in use & $25000 \mathrm{~km}$ \\
\hline Model year & 2008 & 2009 \\
\hline $\begin{array}{c}\text { Exhaust after } \\
\text { treatment system }\end{array}$ & $\begin{array}{c}\text { Oxidation catalytic } \\
\text { converter }\end{array}$ & $\begin{array}{c}\text { Oxidation catalytic } \\
\text { converter +DPF }\end{array}$ \\
\hline
\end{tabular}




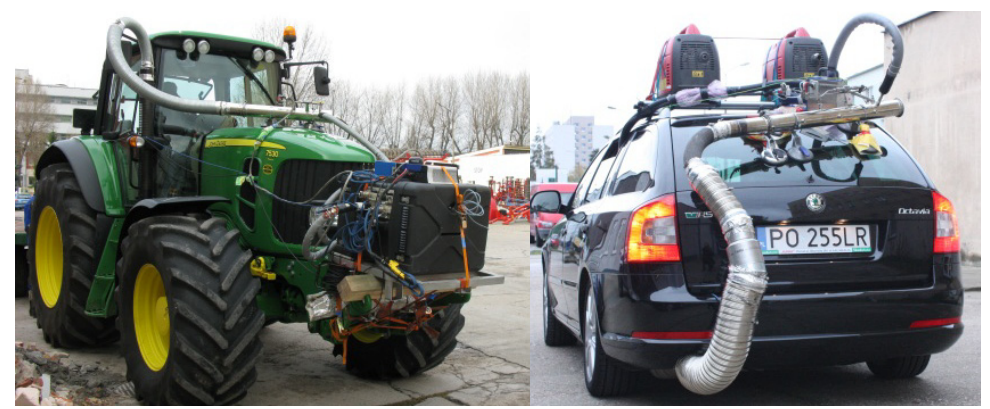

Figure 1: The view of tractor and car with the exhaust emissions measuring equipment fitted during the test.

In order to measure the concentrations of the exhaust emission components a portable exhaust emissions analyzer SEMTECH DS by SENSORS was used (Fig. 2, Tab. 2). The analyzer measures the concentration of the exhaust components and simultaneously measures the flow rate of the exhaust gases. The exhaust gases are introduced into the analyzer through a probe maintaining the

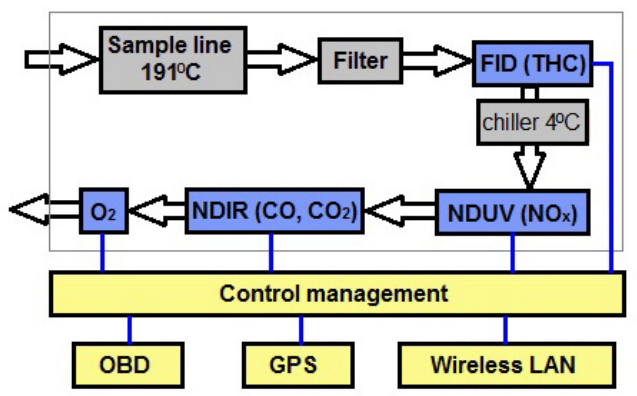

Figure 2: A diagram of a portable analyzer SEMTECH DS; exhaust gas flow channels (arrow) and electrical connections circled (blue line).

Table 2: $\quad$ Characteristics of the portable exhaust analyzer SEMTECH DS.

\begin{tabular}{|c|c|c|}
\hline Parameter name & Measurement method & Accuracy \\
\hline 1. Emissions & NDIR, range 0-8\% & $\pm 3 \%$ \\
$\mathrm{CO}$ & FID, range 0-10.000 ppm & $\pm 2 \%$ \\
$\mathrm{HC}$ & NDUV, range 0-2500 ppm & $\pm 3 \%$ \\
$\mathrm{NO}_{\mathrm{x}}=\mathrm{NO}+\mathrm{NO}_{2}$ & NDIR, range 0-20\% & $\pm 3 \%$ \\
$\mathrm{CO}_{2}$ & Electrochemical, range 0-25\% & $\pm 1 \%$ \\
\hline $\mathrm{O}_{2}$ & Over 10 hours at data acquisition rate of $1 \mathrm{~Hz}$ \\
\hline 2. Data storage & SAE J1850 (PWM), SAE J1979 (VPW) \\
capacity & ISO 14230 (KWP-2000) \\
\hline 3. Vehicle & ISO 15765 (CAN), ISO 11898 (CAN) \\
interface & SAE J1587, SAE J1939 (CAN) \\
compatibility & \multicolumn{2}{|}{}
\end{tabular}


temperature of $191^{\circ} \mathrm{C}$. Then, the particulate matter is filtered out (diesel engines) and the exhaust is directed to the flame-ionizing detector (FID) where HC (Hydrocarbons) concentration is measured. The exhaust gases are then cooled down to the temperature of $4^{\circ} \mathrm{C}$ and the measurement of the concentration of $\mathrm{NO}_{\mathrm{x}}$ (Nitric Oxides, NDUV analyzer), $\mathrm{CO}, \mathrm{CO}_{2}$ (Carbon Monoxide, Carbon Dioxide, NDIR analyzer) and $\mathrm{O}_{2}$ follows in the listed order. It is possible to add data sent directly from the vehicle diagnostic system to the central unit of the analyzer and use the GPS signal (Global Positioning System). The GPS signal is mainly used in the tests of on-road vehicles. In investigations similar to the ones presented here when the vehicle operates in a limited area, on-road emissions are not measured and GPS is of secondary importance. The test did not only comprise the measurements of the emissions but also, for the purpose of comparison, signals from the on-board diagnostic system (engine speed, load, vehicle speed, temperature of intake air). Some of these signals served to specify time density maps presenting the share of the operating time of the vehicles in the actual operation conditions [6-8].

For the measurement of PM (Particulate Matter) SEMTECH-LAM (Laser Aerosol Monitor) was used. SEMTECH-LAM operates through laser light scattering and measures the concentration of fine particulate matter in the exhaust gases in real time. With two selectable ranges and variable dilution ratios, the analyzer is compatible with a variety of different engine types, vehicles and test conditions. It could be used as test stand equipment or for onroad testing. The dual sample port enables testing of filter efficiency, for engines fitted with a diesel particulate filter. The SEMTECH-LAM uses three mass flow controllers that are automatically adjusted to maintain the desired dilution ratio. A pump pulls the diluted sample through the monitor. The monitor contains a laser light scattering analyzer that measures fine particulates from $100 \mathrm{~nm}$ to $10000 \mathrm{~nm}$. The specifications of SEMTECH-LAM have been shown in table 3.

Table 3: $\quad$ The specifications of SMTECH-LAM.

\begin{tabular}{|c|c|}
\hline Measurement Range: & $\begin{array}{c}0 \text { to } 40 \mathrm{mg} / \mathrm{m}^{3} \\
0 \text { to } 700 \mathrm{mg} / \mathrm{m}^{3}\end{array}$ \\
\hline Dilution & Selective Ratio \\
\hline Particle Size & 100 to $10.000 \mathrm{~nm}$ \\
\hline Resolution & $0.01 \mathrm{mg} / \mathrm{m}^{3}$ \\
\hline Drift & $<0.25 \mathrm{mg} / \mathrm{m}^{3}$ over 6 hours \\
\hline Sample flow & $1.5 \mathrm{LPM}$ \\
\hline Sample rate & $5 \mathrm{~Hz}$ (internally to $100 \mathrm{~Hz}$ ) \\
\hline Output & RS232 Analog 0 to $5 \mathrm{VDC}$ option \\
\hline Power supply & 12 to 24 VDC or 110 to 240 VAC \\
\hline Operating temperature & 0 to $40^{\circ} \mathrm{C}$ \\
\hline
\end{tabular}

\section{The results and analysis}

The conducted research enabled an evaluation of the level of exhaust emissions from the tested vehicles. During the tests with the frequency of $1 \mathrm{~Hz}$ the authors recorded the exhaust emissions, exhaust mass flow and data from the on-board diagnostic systems of the vehicles. As for the data pulled from the 
on-board diagnostic systems the data related to the engine operating parameters were particularly important (engine speed and engine load). Equally important data were the speed and location of the vehicle pulled from the GPS system. Based on the above information the on-road emissions of $\mathrm{CO}_{2}, \mathrm{CO}, \mathrm{NO}_{x}, \mathrm{HC}$ and PM were determined for both vehicles. In all cases, the on-road emission values for the passenger vehicle were lower than those of a farm tractor (Fig. 3). The greatest differences were recorded for the on-road emission of $\mathrm{CO}$ and $\mathrm{NO}_{\mathrm{x}}$ (for the passenger vehicle they were lower by 90 and $97 \%$ respectively). The passenger vehicle also had better gas mileage, which was confirmed by a lower on-road emission of $\mathrm{CO}_{2}$. This is important information because the farm tractor carried a load of low weight and the engine did not operate under heavy load. It is noteworthy that non-road vehicles operate in many cities. The engines of these vehicles operate at maximum loads or loads close to maximum. Such operating conditions cause greater fuel consumption. This directly influences the increase in the exhaust emissions. The lack of advanced after treatment systems in farm and construction machines makes the exhaust emissions from these vehicles much higher than it is in the case of on-road vehicles. A good example is the lack of diesel particulate filter in the test farm tractor, which resulted in an increase in the PM emission by 10 times.

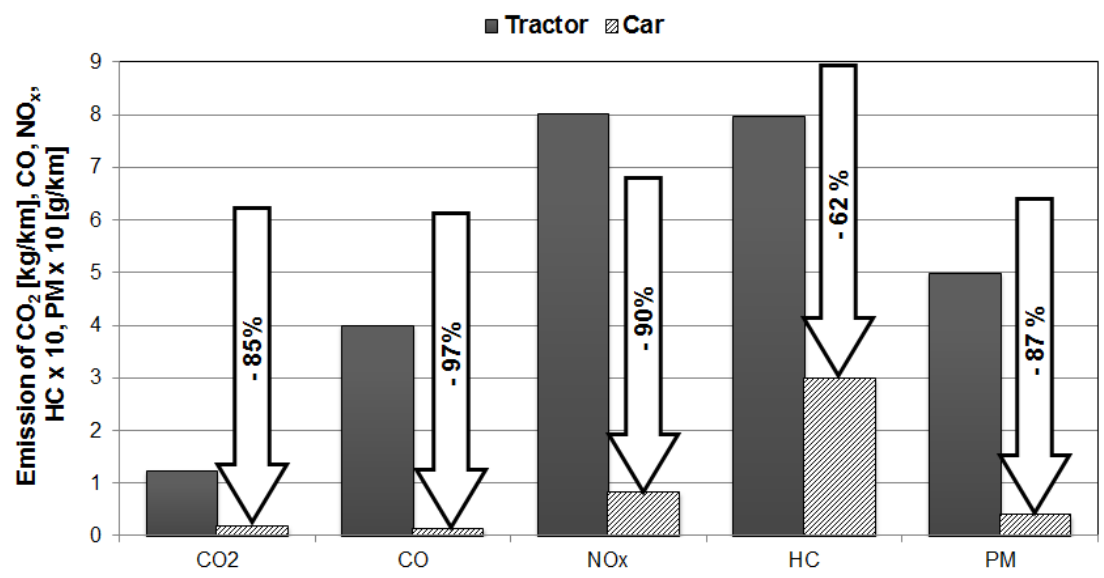

Figure 3: The values of the on-road exhaust emissions of $\mathrm{CO}_{2}, \mathrm{CO}, \mathrm{NO}_{\mathrm{x}}, \mathrm{HC}$ and PM for the tested vehicles.

Many non-road vehicles used in the city are stationary during operation. A good example may be vehicles for maintenance of green areas, vehicles for cleaning purposes or construction machines. In order to show the size of the emission threat from this type of vehicles in figure 4 the authors have shown a comparison of the emission generated in the period of one hour by the tested vehicles. The farm tractor had a higher average hourly emission of $\mathrm{CO}_{2}, \mathrm{CO}$, $\mathrm{NO}_{\mathrm{x}}, \mathrm{HC}$ and $\mathrm{PM}$ - similar to that obtained during on-road tests. A conclusion can be drawn that within one hour the tractor generated a mass of exhaust emissions equal to the mass generated by tens of vehicles and in the case of PM 


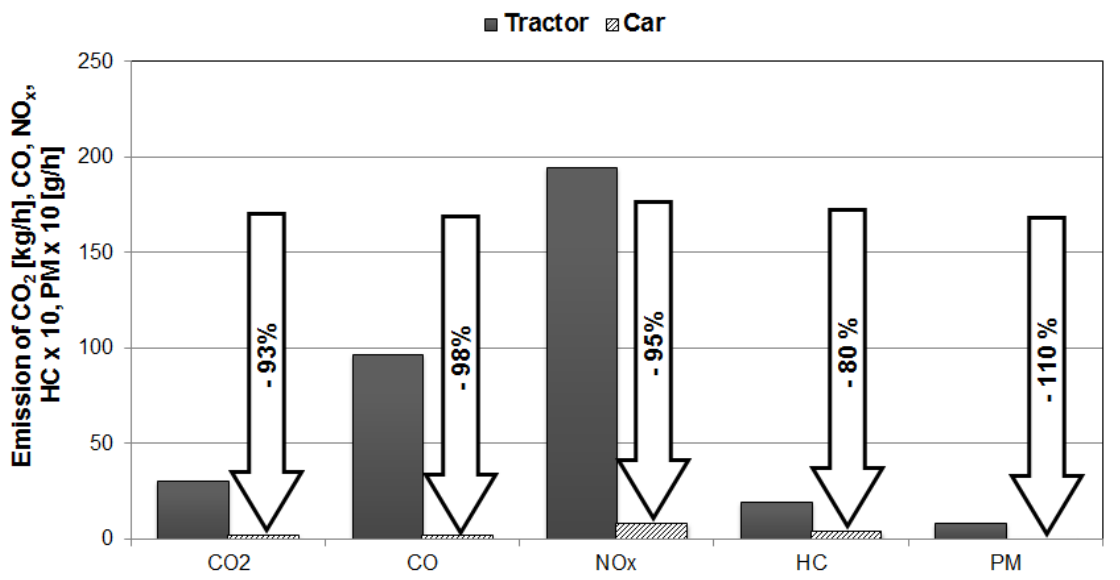

Figure 4: The values of the hourly exhaust emissions of $\mathrm{CO}_{2}, \mathrm{CO}, \mathrm{NO}_{\mathrm{x}}, \mathrm{HC}$ and PM for the tested vehicles.

this is an equivalent of more than a hundred vehicles. This value grows even further for heavily loaded engines e.g. machinery operating on construction sites.

\section{Conclusions}

The conducted tests have confirmed the scale and complexity of the problem of exhaust emissions from non-road vehicles that very often operate in cities. It is very often that a large number of these vehicles are concentrated in a small area. This is a serious problem because non-road vehicles used in the cities are most often operated for several hours per day and they generate a high level of exhaust emissions. Locally, this may result in an increased photochemical smog. One of the possible solutions to this problem is stricter supervision over non-road vehicles used in city areas. Among the solutions we could consider admitting vehicles for operation only if they meet very stringent emission limits (stage IV, Tier 4) or an introduction of machinery modernization schemes based on retrofitting of after treatment systems).

\section{References}

[1] Gao Y., Checkel M.D.: Emission Factors Analysis for Multiple Vehicles Using an On-Board, In-Use Emissions Measurement System. SAE Technical Paper Series 2007-01-1327, (2007).

[2] Gao Y., Checkel M.D., Experimental Measurement of On-Road $\mathrm{CO}_{2}$ Emission and Fuel Consumption Functions, presented at SAE Congress, 2007-01-1610, (2007).

[3] Merkisz J., Pielecha J., Fuc P., Lijewski P., The analysis of the PEMS measurements of the exhaust emissions from city buses using different 
research procedures. The 8th IEEE Vehicle Power and Propulsion Conference VPPC 2012, Org. KIEE, Paper No. F20120618-0339 Seul 912.10.2012, s. 903-907.

[4] Merkisz J., Idzior M., Pielecha J., Gis. W., Emission tests in city buses under real road conditions. Book "Urban Transport XVI - Urban Transport and the Environment in the 21st Century", Edited by A. Pratelli and C.A. Brebbia. WIT Transactions. WIT Press 2010, Wessex, UK, s. 181-189.

[5] Walsh M.P.: Global trends in motor vehicle pollution control; a 2011 update. Part 1. Combustion Engines / Silniki Spalinowe nr 2/2011 (145), p. 106-117, (2011).

[6] Merkisz J., Lijewski P., Fuc P., Pielecha J., Exhaust emission tests from agricultural machinery under real operating conditions. SAE 2010 Commercial Vehicle Engineering Congress, October, 2010, Chicago, IL, USA, 2010, SAE Paper 2010-01-1949.

[7] Merkisz J., Fuc P.: The Exhaust Emission from Light Duty Vehicles in Road Test in Urban Traffic. SAE Technical Paper Series 2010-01-1558, (2010).

[8] Shahinian V. D.: SENSOR tech-ct Update Application Soft-ware for SEMTECH Mobile Emission Analyzers. Sensors 4th Annual SUN (SEMTECH User Network) Conference, 22.10.2007, (2007). 